\title{
Dyslipoproteinemia and an Inhibitor of Lipolytic Enzymes in Weber-Christian Disease
}

\author{
Kohji SHIRAI, Nobuo MATSUOKA*, Pakming WONG, Shigenori FUJIOKA, \\ Yasushi SAITO and Sho YOSHIDA
}

\begin{abstract}
Hyperlipidemia of initially Type $\mathrm{V}$ and finally of Type III was observed in a patient with Weber-Christian disease. The lipoprotein lipase ( $\mathrm{LpL}$ ) and hepatic triglyceride lipase (HTGL) activities of the post-heparin plasma were low, but detectable. Both lipase activities were higher when assayed with $20 \mu l$ of post-heparin plasma than with more than $30 \mu \mathrm{l}$, indicating the presence of some inhibitory factor in the plasma. This plasma inhibited purified LpL and HTGL from human post-heparin plasma. Zonal ultracentrifugation studies showed that the inhibitor of hepatic lipase was associated with the middle fraction of intermediate lipoprotein and low density lipoproteins $(1.020<d<1.040)$. These results are consistent with the idea that dyslipoprotenemia in this patient was partially due to dysfunction of the catabolic system caused with an inhibitor of lipolytic enzymes.
\end{abstract}

Key words: $\quad$ Weber-Christian disease, Type III hyperlipidemia, Inhibitor of lipoprotein lipase, Inhibitor of hepatic lipase

Hyperlipidemia is occasionally observed in Weber-Christian disease (1) but its cause is not clarified. We met a patient with Weber-Christian disease accompanied with lipoprotein abnormalities showing initially an increase in chylomicrons and very low density lipoproteins (VLDL, $\mathrm{d}<1.006$ ) and finally high levels of intermediate density lipoproteins (IDL, $1.006<\mathrm{d}<1.020$ ). One of the causes of hyperlipidemia is a dysfunction of the lipoprotein catabolic system. In a case of hypertriglyceridemia, lipoprotein lipase deficiency or apolipoprotein CII deficiency are pointed out $(2,3)$. Breckenridge et al. report that hepatic triglyceride lipase deficiency is associated with hyperlipidemia characterized by triglyceride-rich low density lipoproteins $(1.019<\mathrm{d}<1.063)(\mathrm{LDL})$, and high density lipoproteins $2(1.063<\mathrm{d}<1.125)\left(\mathrm{HDL}_{2}\right)$, and the presence of $\beta$-VLDL (4). In this paper, we tried to define the cause of hyperlipidemia in Weber-Christian disease from the aspect of catabolic system dysfunction. The post-heparin plasma of this patient showed low activities of both LpL and HTGL activities, and an inhibitory effect against both LpL and HTGL. The property of this inhibitory factor was examined and its influence on the formation of dyslipoprotenemia was discussed.

\section{MATERIALS AND METHODS}

\section{Subject}

A.K., a 28-year-old man had suffered from multiple tender nodules in subcutaneous fat, fever, arthralgia and myalgia for 6 years. Skin biopsy revealed panniculitis adiposus. A diagnosis of Weber-Christian disease was made and a large dose of corticosteroid was administered. As a result the fever subsided and the subcutaneous nodules dis-

From The Second Department of Internal Medicine, Chiba University, School of Medicine, Chiba and

*Kawatetsu General Hospital, Chiba

Received for publication July 4, 1988.

Reprint request to: Kohji Shirai, MD, The Second Department of Internal Medicine,

Chiba University, School of Medicine, 1-8-1 Inohana, Chiba 280, Japan 
appeared intermittently. He gradually lost the subcutaneous adipose tissue of the face and extremities. The patient was $160 \mathrm{~cm}$ tall, and during treatment his weight decreased from 62 to $45 \mathrm{~kg}$. He had also suffered from a lung abscess due to salmonella sepsis during the previous 4 years. He had hepatomegaly and liver function tests showed elevated levels of transaminase, GOT, GPT, alkaline phosphatase and low choline esterase. Icterus occurred. Glucose intolerance was not observed.

Leukopenia and thrombopenia had appeared 6 months previously and severe hypertriglyceridemia developed although prednisolone $(15 \mathrm{mg} /$ day) was administered samely as before. No xanthoma was observed. There was no family history of hyperlipidemia.

\section{Clinical chemistry}

Routine laboratory tests gave the following results: red blood cells $3,030,000 / \mathrm{mm}^{3}$, white blood cells $1100 / \mathrm{mm}^{3}$, platelets $54000 / \mathrm{mm}^{3}$, no abnormal young cells. The maximum total cholesterol level (T.ch) was $317 \mathrm{mg} / \mathrm{dl}$ and that of triglyceride (TG) was $1275 \mathrm{mg} / \mathrm{dl}$ and these levels decreased to 182 nd 279, respectively, during low food intake caused by deteriorated liver function. The results of liver function tests were as follows: GOT 360U (0-45), GPT 370U (0-45), Al-p 569U $(<100)$, choline esterase $4.45 \mathrm{U}(3.5-7.5)$, total bilirubin $4.5 \mathrm{mg} / \mathrm{dl}$, indirect bilirubin $1.5 \mathrm{mg} / \mathrm{dl}$. The levels of urea nitrogen and creatinine were normal and urinalysis showed a trace of protein, no blood cells, and no abnormal sediment. Coagulation tests showed decrease in the fibrinogen level, increase in the level of fibrin degradative product $(40 \mu \mathrm{g} / \mathrm{ml})$ and a prolonged prothrombin time $(37.8 \mathrm{sec})$, indicating disseminated intravascular coagulopathy occurred. Several bone marrow punctures were dry taps. Tests for rheumatoid arthritis and anti-nuclear antibody gave negative results. The levels of $\operatorname{IgG}, \operatorname{IgM}$, and IgA were within normal ranges. The erythrocyte sedimentation rate was high, but was $6 \mathrm{~mm} / \mathrm{hr}$ in the last 3 months.

\section{Lipoprotein analysis}

Serum lipoprotein was fractionated by ultracentrifugation in a Beckman type $42 \mathrm{LpTi}$ rotor according to the method of Bronzert (5). Serum itself $(d=1.006)$, and serum adjusted to a density of 1,063 with potassium bromide were centrifuged at 41,000 rpm $(222,000 \mathrm{~g})$ for 3 hours. The lipid contents of the bottom fractions of the preparations, and of the original whole serum were determined. The lipid content of the bottom fraction of $d=1.063$ was that of high density lipoproteins (HDL). The lipid contents of low density lipoproteins (LDL, 1.006 $\mathrm{mg} / \mathrm{dl}<\mathrm{d}<1.063 \mathrm{mg} / \mathrm{dl}$ ) was calculated by subtracting the contents in $\mathrm{d}=1.063$ bottom fraction from that in $d=1.006$ bottom fraction. Similarly the lipid in the very low density lipoprotein (VLDL) fraction was calculated by subtracting the contents in $\mathrm{d}=1.006 \mathrm{mg} / \mathrm{dl}$ bottom fraction from that in original serum. The separation of VLDL, LDL and HDL was confirmed using dye. Zonal ultracentrifugal separation of serum was performed in a Beckman Til4 rotor by the method of Patch et al. (6). A density gradient was formed with $\mathrm{NaBr}$ solution of $\mathrm{d}=1.000$ and $\mathrm{d}=1.300$ using a gradient pump (Beckman).

\section{Determination of apolipoproteins}

Plasma apolipoproteins were determined quantitatively by the single radial immunodiffusion methods. Assay kits for apolipoproteins AI, AII, B, $\mathrm{CII}$ and $\mathrm{E}$ were provided by Daiichi Chemical Company (Tokyo, Japan). Apolipoprotein E subclasses of VLDL was determined by isoelectric focusing by the method of Falko et al. (7).

\section{Lipid and chemical analysis}

Total cholesterol was assayed enzymatically with cholesterol esterase, cholesterol oxidase and peroxidase (8). Triglyceride was measured enzymatically with lipoprotein lipase, glycerol dehydrogenase and diaphorase (9). Phospholipids were determined as phospholipids containing choline. All phospholipids containing choline were assayed enzymatically with phospholipase $\mathrm{D}$ and choline oxidase (10). Protein was measured by the method of Lowry et al. (11).

\section{Post-heparin lipolytic activity}

The lipase activities in post-heparin plasma were determined as follows. Ten units of heparin per $\mathrm{kg}$ body weight was given intravenously and venous blood sample was obtained $10 \mathrm{~min}$ later. The plasma was stored at $-20^{\circ} \mathrm{C}$ until assayed. Hepatic lipase activity was taken as the activity remaining after 
inactivation in the $\mathrm{LpL}$ with $1 \mathrm{M} \mathrm{NaCl}$ (12). Lipoprotein lipase activity was taken as the difference between the total activity and remaining activity after inactivation with $1 \mathrm{M} \mathrm{NaCl}$. The reaction mixture contained 337 nmoles of tri $\left[{ }^{14} \mathrm{C}\right]$ oleoyl glycerol, $0.01 \%$ Triton $\mathrm{X}-100$ and $2 \%$ fatty acid free-bovine serum albumin and post-heparin plasma (usually $20 \mu \mathrm{l}$ ) in $250 \mu \mathrm{l}$ of $100 \mathrm{mM}$ Tris $\mathrm{HCl}$ buffer, $\mathrm{pH}$ 8.4. Apolipoprotein CII $(2 \mu \mathrm{g})$, an activator for lipoprotein lipase, was added to the reaction mixture for measurement of total lipolytic activity. After incubation for $30 \mathrm{~min}$ at $37^{\circ} \mathrm{C}$, the reaction was stopped by addition of $2.25 \mathrm{ml}$ of chloroform/methanol/heptane (10:9:7) and $1 \mathrm{ml}$ of $0.1 \mathrm{~N} \mathrm{NaOH}(13) .\left[{ }^{14} \mathrm{C}\right]$ Oleic acid was extracted into the upper phase and its radioactivity was counted.

\section{Purifications of lipoprotein lipase and hepatic triglyceride lipase}

Lipoprotein lipase and hepatic triglyceride lipase were purified from human post-heparin plasma by affinity chromatography on heparin-Sepharose (14) as described by Greten and Walter (15) and Baginsky and Brown (16). The fraction eluted with 0.7 $\mathrm{M} \mathrm{NaCl}$ was used as hepatic triglyceride lipase, and that eluted with $1.5 \mathrm{M} \mathrm{NaCl}$ as lipoprotein lipase. These fractions were stored in $50 \%$ glycerol at $-70^{\circ} \mathrm{C}$. The enzyme preparation showed the characteristic properties of lipoprotein lipase $(13,15$, 16).

\section{Tributyrin hydrolyzing activity}

To determine the hydrolyzing activity of monomeric substrate by hepatic lipase and lipoprotein lipase, $\left[{ }^{14} \mathrm{C}\right]$ tributyrin was used as a substrate, and the assay procedures were performed according to the method described by previous report (21).

\section{Gel filtration of plasma}

Gel filtration of plasma was performed on an Ultrogel ACA 22 column $(2.5 \mathrm{~cm} \times 30 \mathrm{~cm})$. Material was eluted with $0.9 \% \mathrm{NaCl}$ in $10 \mathrm{mM}$ Tris$\mathrm{HCl}$ buffer, $\mathrm{pH} 7.4$, containing $1 \mathrm{mM}$ EDTA and $0.01 \mathrm{NaN}_{3}$ at a flow rate of $10 \mathrm{ml} / \mathrm{hr}$, and fractions of $2.5 \mathrm{ml}$ were collected.

\section{RESULTS}

\section{Profiles of lipoprotein lipids and apolipoproteins of the patient}

The lipoprotein fractionations when the patient's serum triglyceride level was $729 \mathrm{mg} / \mathrm{dl}$ and the total cholesterol level was $278 \mathrm{mg} / \mathrm{dl}$ are shown in Table 1. In the lipoprotein fraction of $\mathrm{d}<1.006 \mathrm{mg} / \mathrm{ml}$, the triglyceride level was markedly elevated, and the total cholesterol and phospholipid level were also increased. The ratio of the triglyceride to the total cholesterol content was high. Agarose electrophoresis of serum after $12 \mathrm{hr}$ starvation showed the presence of lipid at the origin, indicating the presence of chylomicrons. In the fraction of $1.006<d<$ 1.063 , the triglyceride, cholesterol and phospholipid levels were increased, the level of triglyceride being especially high indicating the presence of in-

Table 1. Lipid Concentrations in Various Lipoprotein Fractionations

\begin{tabular}{rlrrrr}
\hline \multicolumn{1}{c}{ Density } & Date & $\begin{array}{c}\text { Total Cholesterol } \\
(\mathrm{mg} / \mathrm{dl})\end{array}$ & $\begin{array}{c}\text { Triglyceride } \\
(\mathrm{mg} / \mathrm{dl})\end{array}$ & $\begin{array}{c}\text { Phospholipids } \\
(\mathrm{mg} / \mathrm{dl})\end{array}$ \\
\hline -1.006 & Aug. 20 & 120 & $(23 \pm 10)^{*}$ & $612(80 \pm 45)$ & $262(45 \pm 20)$ \\
(mg/dl) & Nov. 13 & 36 & 42 & 13 \\
$1.006-1.063$ & Aug. 20 & $136(111 \pm 29)$ & $111(26 \pm 8)$ & $114(78 \pm 17)$ \\
& Nov. 13 & 119 & 221 & 224 \\
$1.063-1.21$ & Aug. 22 & 22 & $(45 \pm 10)$ & $6(16 \pm 4)$ & $47(89 \pm 15)$ \\
& Nov. 13 & 28 & 16 & 45 \\
\hline \multirow{2}{*}{ Total } & Aug. 20 & 278 & \multicolumn{2}{c}{729} & 423 \\
\hline
\end{tabular}

*Normal ranges were obtained from 49 healthy men without hyperlipidemia, and the values are shown by mean \pm standard deviation (SD). 
Dyslipoproteinemia in Weber-Christian Disease

Table 2. Apolipoproteins in Patient's Serum

\begin{tabular}{ccc}
\hline \multirow{2}{*}{ Apolipoprotein } & \multicolumn{2}{c}{ Concentration $(\mathrm{mg} / \mathrm{dl})$} \\
\cline { 2 - 3 } & Patient & Control \\
\hline Apo A-I & 24 & $125 \pm 25^{*}$ \\
A-II & 18 & $28.2 \pm 6.4$ \\
B & 95 & $72.3 \pm 16.5$ \\
C-II & 4.4 & $3.8 \pm 1.7$ \\
E & 12.5 & $3.8 \pm 0.9$ \\
\hline
\end{tabular}

The serum sample from the patient was obtained on Nov. 13 as for Table 1 . The value of control was obtained from normal healthy 120 persons.

* $=$ mean \pm standard deviation.

termediate density lipoproteins $(1.006<\mathrm{d}<1.019)$.

The general condition of the patient gradually deteriorated. After 2 months of low food intake, his triglyceride level had decreased to $279 \mathrm{mg} / \mathrm{dl}$ and his total cholesterol level to $183 \mathrm{mg} / \mathrm{dl}$, as shown in Table 1. In the fraction of $\mathrm{d}<1.006 \mathrm{mg} / \mathrm{ml}$, the triglyceride level was low, but that of total cholesterol was still high, indicating the presence of cholesterol-rich particles. In the fraction of $1.006<\mathrm{d}<1.063 \mathrm{mg} / \mathrm{ml}$, the triglyceride level was high compared to that of total cholesterol. In the fraction of $1.063<\mathrm{d}<1.21 \mathrm{mg} / \mathrm{ml}$, the total cholesterol level was still low.

Results of zonal ultracentrifugal analysis at a later date are shown in Fig. 1 comparing with those of a normal subject and of Type III patient with apolipoprotein E phenotype2/2. The high total cholesterol level in the intermediate fraction of 1.006 $\mathrm{mg} / \mathrm{ml}<\mathrm{d}<1.012 \mathrm{mg} / \mathrm{ml}$ was eluted like that of the Type III patient rather than the Type IV patient, indicating the presence of IDL. These results indicate that the phenotype of this hyperlipidemia was initially Type $\mathrm{V}$ and later Type III. The apolipoprotein levels on the second examination are shown in Table 2. There was no deficiency of apolipoprotein C-II $(4.4 \mathrm{mg} / \mathrm{dl})$. The apolipoprotein A-I and A-II levels were low, and the apolipoprotein $\mathrm{E}$ level was high. Isoelectric focusing electrophoresis of apo VLDL show the apolipoprotein $E$ isoform 3/4.

\section{Lipoprotein lipase and hepatic triglyceride lipase in post-heparin plasma}

The LpL and HTGL activities in post-heparin plasma were very low, then they were measured

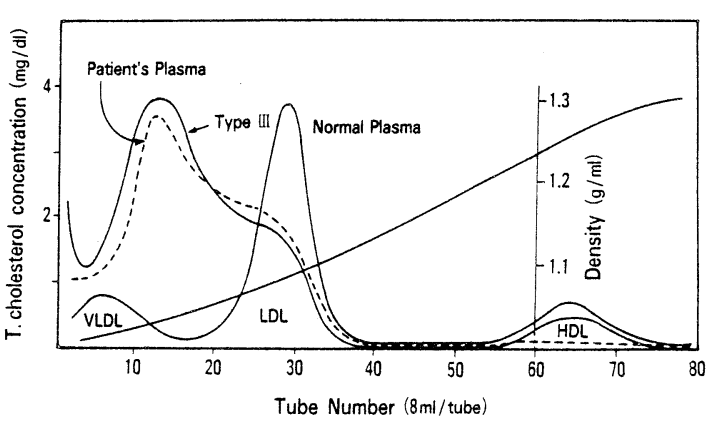

Fig. 1. Zonal ultracentrifugal analysis of plasma of the patient with Weber-Christian Disease.

Normal plasma $(20 \mathrm{ml})$, Type III patient plasma $(\mathrm{TG}=729 \mathrm{mg} / \mathrm{dl}, \mathrm{t} . \mathrm{ch}=429 \mathrm{mg} / \mathrm{dl})(7 \mathrm{ml})$, and the patient's plasma $(\mathrm{TG}=279$, $\mathrm{T} . \mathrm{ch}=182)(20 \mathrm{ml})$ were subjected to zonal ultracentrifugation in Beckman Ti 42 Rotor. The density gradient was formed with $\mathrm{NaBr}$ of $\mathrm{d}=1.0$ and $\mathrm{d}=1.3$, using a Beckman Gradient Maker by the method of Patsch et al. (6).
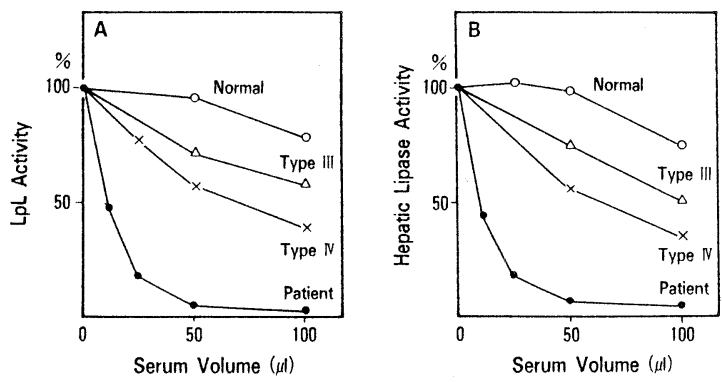

Fig. 2. Effects of sera from patients with various hyperlipidemic diseases on purified $\mathrm{LpL}$ (A) and purified HTGL (B). Incubations were performed as described under Materials and Methods. Serum lipid levels were as follows; In Type III patient serum, triglyceride $=729 \mathrm{mg} / \mathrm{dl}$, total cholesterol $=429 \mathrm{mg} / \mathrm{dl}$ and in Type IV patient's serum triglyceride $704 \mathrm{mg} / \mathrm{dl}$, total cholesterol $=329 \mathrm{mg} / \mathrm{dl}$, in patient's serum triglyceride $=279 \mathrm{mg} / \mathrm{dl}$, total cholesterol $176 \mathrm{mg} / \mathrm{dl}$.

using $30 \mu 1$ of post-heparin plasma. But, these activities were detected when measured using less than $20 \mu 1$ of the post-heparin plasma, as shown in Table 3. The activities were higher when assayed with $5 \mu 1$ of the post-heparin plasma than with 10 or $20 \mu 1$. Thus the low activities of both $\mathrm{LpL}$ and HTGL were not due to enzyme deficiency, but to an inhibitor in post-heparin plasma.

\section{Effect of serum on LpL and HTGL activities}

There are several reports describing inhibitory factors against lypolytic enzyme activities in the 
Table 3. LpL and HTGL Activities in Post-heparin Plasma

\begin{tabular}{|c|c|c|c|c|}
\hline \multirow{2}{*}{$\begin{array}{l}\text { Plasma volume in } \\
\text { assay mixture }\end{array}$} & \multicolumn{4}{|c|}{ LpL activity ( $\mathrm{nmol} / \mathrm{hr}$ ) HTGL activity ( $\mathrm{nmol} / \mathrm{hr}$ ) } \\
\hline & Patient & Control & Patient & Control \\
\hline 100 & 0 & $120 \pm 34$ & 0 & $190 \pm 25$ \\
\hline 75 & 2 & $110 \pm 32$ & 0 & $182 \pm 24$ \\
\hline 50 & 0 & $100 \pm 34$ & 3 & $164 \pm 22$ \\
\hline 40 & 6 & $92 \pm 32$ & 5 & $152 \pm 20$ \\
\hline 30 & 8 & $80 \pm 24$ & 10 & $128 \pm 17$ \\
\hline 20 & 19.9 & $68 \pm 24$ & 16 & $110 \pm 14$ \\
\hline 10 & 31 & $40 \pm 12$ & 24 & $72 \pm 10$ \\
\hline 6 & 25 & $22 \pm 6$ & 12 & $42 \pm 6$ \\
\hline
\end{tabular}

Incubations were performed as described under Materials and Methods. Post-heparin plasma was obtained at mild liver dysfunction $(\mathrm{ChE}=4.45 \mathrm{U}$ (normal range = 3.5-7.5).

plasma $(4,17,18)$. To evaluate the specificity of the inhibitory factor in the patient's plasma, we examined the effects of various hyperlipidemic sera on the activities of purified LpL and HTGL.

As shown in Fig. 2, the patient's serum ( $\mathrm{TG}=279$ $\mathrm{mg} / \mathrm{dl}, \mathrm{T} . \mathrm{ch}=182 \mathrm{mg} / \mathrm{dl}$ ) cause dose-dependent decreases in both LpL and HTGL activity. A volume of $100 \mu \mathrm{l}$ of control serum $(\mathrm{TG}=120 \mathrm{mg} / \mathrm{dl}$, t.ch $=176 \mathrm{mg} / \mathrm{dl}$ ) caused about $20 \%$ decrease. Volumes of $100 \mu \mathrm{l}$ of Type III $(\mathrm{TG}=729 \mathrm{mg} / \mathrm{dl}$, $\mathrm{T}$.ch $=429 \mathrm{mg} / \mathrm{dl})$ and Type IV $(\mathrm{TG}=704 \mathrm{mg} / \mathrm{dl}$, T.ch $329 \mathrm{mg} / \mathrm{dl}$ ) sera decreased the LpL and HTGL activities about $50 \%$ to $60 \%$, and $50 \mu 1$ decreased the activities to $25 \%$ to $45 \%$. These inhibition rates were far less than those by the patient's serum.

\section{Characteristics of the inhibitor against $L p L$ and HTGL}

The properties of inhibitory factor were examined using purified HTGL. As shown in Table 4, the inhibitory activity was decreased by heationg the postheparin plasma at $80^{\circ} \mathrm{C}$ for $30 \mathrm{~min}$. The activity was not affected by dialysis in tubing permeable to molecules of less than 18000 daltons, and was not lost on treatment with trypsin $(100 \mu \mathrm{g} / \mathrm{ml})$ for 20 $\min$ at $37^{\circ} \mathrm{C}$. However, freezing and thawing decreased the inhibitory activity slightly.

\section{Localization of the inhibitor of $H T G L$}

On an Ultrogel ACA 22 column chromatography of the patient's plasma the inhibitory activity against HTGL was eluted associating with the lipoprotein

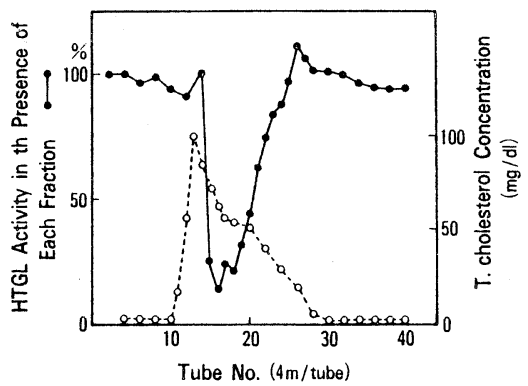

Fig. 3. Ultrogel ACA 22 gel filtration profile of the patient's plasma and the inhibitor of HTGL.

The patient's plasma $(\mathrm{TG}=279$, T.ch $=182,4$ $\mathrm{ml})$ was applied to a column of Ultrogel ACA $22(2.0 \times 30$ $\mathrm{cm}$ ) and material was eluted with $0.9 \% \mathrm{NaCl}, 10 \mathrm{mM}$ Tris$\mathrm{HCl}$ buffer, $\mathrm{pH}$ 7.4. Twenty $\mu \mathrm{l}$ of each fraction was incubated with HTG $(10 \mu \mathrm{g})$ and triolein hydrolyzing activity was determined as described under Materials and Methods.

fraction (Fig. 3). This fraction also inhibited purified LpL activity (data not shown). Zonal ultracentrifugal analysis showed that the inhibitor was associated with fractions between IDL and LDL (Fig. 4). Addition all effect of various other lipoproteins to lipase reaction mixtures were shown in Table V. VLDL and LDL from patients and type III hyperlipidemia (apoE2/2) had scarcely affected LgL and HTGL activities. But, patient's IDL fraction inhibited LpL and HTGL activities, and IDL from type III did not inhibited. 


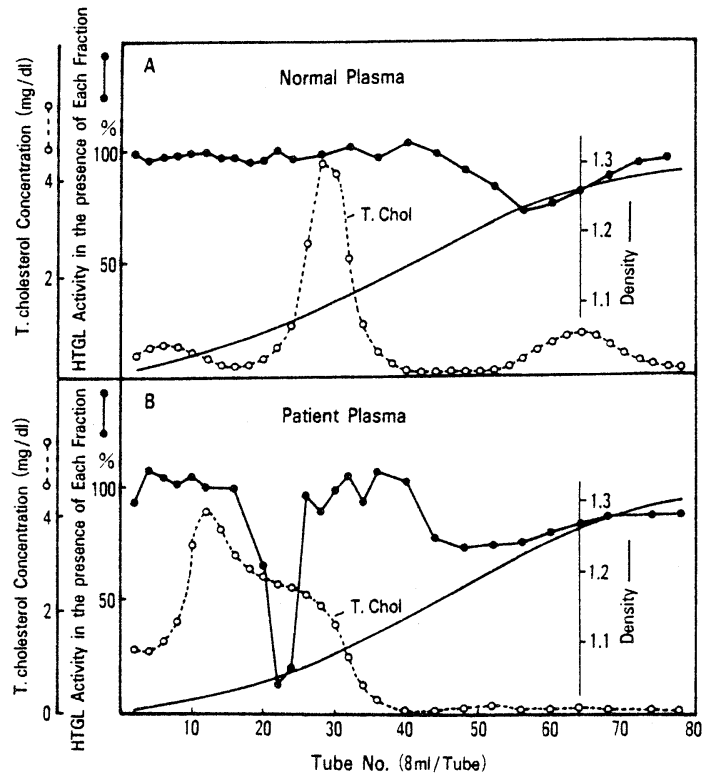

Fig. 4. Zonal ultracentrifugation of plasma of the patient with Weber-Christian disease, and the inhibitor of hepatic triglyceride lipase activity.

Volumes of $20 \mathrm{ml}$ of normal plasma (Fig. 4A) and the patient's plasma (Fig. 4B) were subjected to zonal ultracentrifugation in a Beckman Ti 42 rotor as for Fig. 1. Fifty $\mu 1$ of each fraction was incubated with purified HTGL (5 $\mu \mathrm{g})$ and triolein hydrolyzing activity were determined as described under Materials and Methods.

\section{Effects of inhibitor on tributyrin and triolein hydrolyzing activities of $L p L$ and $H T G L$}

In the presence of inhibitor $(20 \mu \mathrm{g})$, triolein hydrolyzing activities of $\mathrm{LpL}$ and HTGL were decreased as shown in Table VI, but tributyrin hydrolyzing activities of $\mathrm{LpL}$ and HTGL were not decreased.

\section{DISCUSSION}

This report describes a case of Weber Christian disease associated with hyperlipoproteinemia. The plasma was rich in VLDL and triglyceride-rich LDL, and poor in HDL. IDL was present even after a period of low food intake.

The administration of large dose of glucocorticoid is well known to cause hyperlipidemia (24). In this case, the dose of prednisolone $(15 \mathrm{mg} /$ day) was not so large, and severe hyperlipidemia occurred during the same maintenance dose of prednisolone. Therefore, it is suggested that the effect of gluco-
Table 4. Effect of various treatment on inhibitory factor against LpL and HTGL activities

\begin{tabular}{lcc}
\hline $\begin{array}{l}\text { Treatment of } \\
\text { inhibitory factor }\end{array}$ & $\begin{array}{l}\text { LpL } \\
\text { activity }\end{array}$ & $\begin{array}{l}\text { HTGL } \\
\text { activity }\end{array}$ \\
\hline None & 12 & 5 \\
Heating $\left(80^{\circ} \mathrm{C}, 30 \mathrm{~min}\right)$ & 60 & 56 \\
Dialysis & 12 & 5 \\
Freezing and thawing & 24 & 28 \\
Tripsin treatment & 6 & 2 \\
$(1000 \mu \mathrm{g} / \mathrm{ml}, 30 \mathrm{~min})$ & & \\
\hline no inhibitory factor & $100 \%$ & $100 \%$ \\
\hline
\end{tabular}

Inhibitory factor $(20 \mu \mathrm{g})$ obtained from tube No. 22 in Fig. 4 , was treated as shown above and was mixed with purified LpL (8 $\mu \mathrm{g})$ or HTGL $(10 \mu \mathrm{g})$, and tri $\left[{ }^{14} \mathrm{C}\right]$ olelylglycerol, $2 \%$ bovine serum albumin and $0.1 \mathrm{M}$ Tris- $\mathrm{HCl}, \mathrm{pH} 8.3$, with $2 \mu \mathrm{g}$ of apolipoprotein C-II for measurement of $\mathrm{LpL}$. Incubations were for $60 \mathrm{~min}$ at $37^{\circ} \mathrm{C}$.

cortioid is not a main cause of hyperlipidemia in this patient.

It is known that several factors such as lipolytic enzymes and apolipoproteins, are involved in catabolic system of VLDL and IDL. In this patient, apolipoprotein CII was present and apolipoprotein $E$ isoform was not $2 / 2$, and both LpL and HTGL activities were detectable when measured using small amount of post-heparin plasma. But, lipolytic activity was barely detectable when measured using a large amount of post-heparin plasma, indicating the presence of inhibitor against both lipases. This inhibitory effect of serum might partly be by substrate dilution, but the inhibitory effect of serum from this Weber Christian disease patient was far more than those by sera of Type III and Type IV patients, which had even higher triglyceride contents than that of the patient as shown in Fig. 2.

Brunzell et al. report the presence of an inhibitor of $\mathrm{LpL}$ in the plasma of cases of familial chylomicronemia (17). Therefore, hypertriglyceridemia observed in this case with Weber-Christian disease (at Aug. 20 in Table 1) might be due to LpL dysfunction caused by the presence of the inhibitor.

Breckenridge et al. report abnormalities of lipoprotein associated with familial deficiency of hepatic lipase (4). Their patient shows an abnormally high proportion of triglyceride in LDL and the presence of $\beta$-VLDL. Goldberg et al. (19) report that injection of anti-HTGL caused an increase in 
Table 5. Effect of various lipoprotein fractions on $\mathrm{LgL}$ and HTGL activity

\begin{tabular}{|c|c|c|}
\hline \multirow{2}{*}{ Added lipoproteins } & \multicolumn{2}{|c|}{ Remaining Activity } \\
\hline & $\mathrm{LpL}$ & HTGL \\
\hline No addition & $100 \%$ & $100 \%$ \\
\hline \multicolumn{3}{|l|}{ The patient's } \\
\hline VLDL & 84 & 92 \\
\hline IDL & 24 & 21 \\
\hline LDL & 88 & 84 \\
\hline \multicolumn{3}{|c|}{ Type III patient's (apoE2/2) } \\
\hline VLDL & 78 & 94 \\
\hline IDL & 76 & 84 \\
\hline LDL & 85 & 88 \\
\hline
\end{tabular}

The added amount of all lipoprotein's were $30 \mu \mathrm{g}$ of total cholesterol. The reaction conditions were the same as described in Table IV.

triglyceride-rich intermediate lipoprotein particles. These evidences indicate that clearance of IDL requires HTGL activity, and the elevated IDL in our patient might be explained by HTGL dysfunction caused by the inhibitor. To clarify the precise mechanism of the inhibitory factor, the inhibitor was purified. The inhibitor was associated with the IDL fraction (Fig. 4). The specificity of this inhibitory factor was compared with IDL from type III (apoE 2/2) patient (Table 5). IDL from the patient had stronger inhibitory effect than those from Type III patient.

Next, the properties of the inhibitory factor in this patient were compared with those in previous reports. An inhibitor of lipolytic activity in postheparin plasma is reported to be associated with lipoproteins $(\mathrm{d}<1.25 \mathrm{~g} / \mathrm{ml})$ in a hepatic lipase deficient patient (4). Kubo et al. (18) report that apolipoprotein A-I and apolipoprotein A-II inhibit HTGL. In the serum of our patients, the apolipoprotein A-I and apolipoprotein A-II levels were low, and the IDL fraction did not contain apolipoprotein AI or apolipoprotein A-II, indicating that the inhibitor was not apolipoprotein A-I or apolipoprotein A-II. The effects of various treatments shown in Table 4 indicated that the inhibitor might be some protein that was insensitive to trypsin. The relation between the presence of disseminated intravascular coagulopathy and the inhibitor is obscure.

The change of the dyslipoproteinemic pattern from Type V to Type III looks curious. At the stage of type V, IDL were supposed to be included in addition to chylomicrons and VLDL, because LDL $(1.006<\mathrm{d}<1.063)$ was rich in triglyceride. At that time, productions of chylomicrons and VLDL were sufficient because the patient's general condition was good and food intake was sufficient. But after about one month of low food intake, VLDL production decreased, and accumulation of IDL were supposed to become prominent.

The inhibitions of both LpL and HTGL by this factor suggest that common functional units of $\mathrm{LpL}$ and HTGL was susceptible to the inhibitor. To evaluate the mechanism of inhibitory effect, the effects of inhibitor on triolein and tributyrin hydrolyzing activities were studied on the base of hypothesis that LpL and HTGL enzyme molecules are composed of catalytic site and lipid interface recognition site $(20,21,22)$. Namely, monomeric substrate tributryin could be hydrolyzed by catalytic site alone, but triolein hydrolysis requires both catalytic site and lipid interface recognition site (21, 22). Therefore, if the inhibitor works on lipid interface recognition site, tributyrin hydrolysis could not be disturbed, but triolein hydrolysis could be im-

Table 6. Effect of inhibitory factor on tributyrin hydrolyzing activity and triolein hydrolyzing activity of LpL and HTGL.

\begin{tabular}{cccccc}
\hline \multirow{2}{*}{ Inhibitor } & \multicolumn{2}{c}{$\mathrm{LpL}$} & & \multicolumn{2}{c}{ HTGL } \\
\cline { 2 - 3 } \cline { 5 - 6 } & $\begin{array}{c}\text { triolein } \\
\text { hydrolysis }\end{array}$ & $\begin{array}{l}\text { tributyrin } \\
\text { hydrolysis }\end{array}$ & & $\begin{array}{l}\text { triolein } \\
\text { hydrolysis }\end{array}$ & $\begin{array}{l}\text { tributyrin } \\
\text { hydrolysis }\end{array}$ \\
\hline 0 & $100 \%$ & $100 \%$ & & $100 \%$ & $100 \%$ \\
$20 \mu \mathrm{g}$ & $12 \%$ & $98 \%$ & & $5 \%$ & $102 \%$ \\
\hline
\end{tabular}

Assay conditions were the same as in Table IV. 
paired. As shown in Table VI, the inhibitor decreased only triolein hydrolyzing activities of both lipases, but not tributyrin hydrolyzing activities of both lipases. These results suggest that the inhibitor may work on the lipid interface recognition site of LpL and HTGL, but not catalytic site. These similar effects on LpL and HTGL may indicate that $\mathrm{LpL}$ and HTGL molecule, especially the region of lipid interface recognition site may be very similar as suggested by LpL and HTGL amino acid sequence analysis (23). The properties of the inhibitor is still not defined. The origin of this inhibitor may be related to some immunoglobulin, which is supposed to relate to paniculitis, but no precise data was not available yet.

\section{REFERENCES}

1) Miyasaki K, Ooiso Y, Nakamura I, et al: An unusual case which began with subcutaneous panniculitis followed by fever, severe hepatic involvement and hyperlipidemia. Acta Path Jap 27: 213, 1977.

2) Fredrickson DS, Levy RI: Familial hyperlipoproteinemia. In: Stanbury JB, Wyngaarden JB, Fredrickson DS eds: The Metabolic Basis of Inherited Disease. New York: McGraw-Hill: 545, 1972.

3) Breckenridge WC, Little JA, Steiner G, et al: Hypertriglyceridemia associated with deficiency of apolipoprotein C-II. N Engl J Med 298: 1265, 1978.

4) Breckenridge WC, Little JA, Alaupovic P, et al: Lipoprotein abnormalities associated with a familial deficiency of hepatic lipase. Atherosclerosis 45: 161, 1982.

5) Bronzert $\mathrm{TJ}$, Brewer HB: New micromethod for measuring cholesterol in plasma lipoprotein fractions. Clin Chem 23: 2089, 1977.

6) Patch W, Patsch JR, Kostner GM, et al: Isolation of subfractions of human very low density lipoproteins by zonal ultracentrifugation. J Biol Chem 254: 4911, 1978.

7) Falko JM, Schonfeld G, Witztum JL, et al: Effects of estrogen therapy on apolipoprotein $\mathrm{E}$ in type III hyperlipoproteinemia. Metabolism 28: 1171, 1979.

8) Allain C: Enzymatic determination of total serum cholesterol. Clin Chem 20: 470, 1974.

9) Tiffany KO: Clinical evaluation of kinetic enzymatic fixed time. Clin Chem 2: 476, 1974.
10) Takayama $M$, Itoh $S$, Nagasaki $T$, et al: A new enzymatic method for determination of serum cholinecontaining phospholipids. Clin Chim Acta 79: 93, 1977.

11) Lowry $\mathrm{OH}$, Rosebrough $\mathrm{NJ}$, Farr AL, et al: Protein measurement with the flin phenol reagent. J Biol Chem 193: $265,1951$.

12) Fielding CJ, Fielding PE: Mechanism of salt-mediated inhibition of lipoprotein lipase. J Lipid Res 17: 248, 1976.

13) Belfrage $P$, Vaughan $M$ : Simple liquid-liquid partition system for isolation of labeled oleic acid from mixtures with glycerides. J Lipid Res 10: 341, 1969.

14) Iverius $\mathrm{PH}$ : Coupling of glycosaminoglycans to agarose beads (Sepharose 4B). Biochem J 124: 677, 1971.

15) Greten H, Walter B: Purification of a human postheparin plasma triglyceride lipase. FEBS Letters 27: 306, 1972.

16) Baginsky LM, Brown MV: Differential characteristics of purified hepatic triglyceride lipase and lipoprotein lipase from human post-heparin plasma. J Lipid Res 18: 423, 1977.

17) Brunzell JD, Miller NE, Alaupovic $P$, et al: Familial chylomicronemia due to a circulating inhibitor of lipoprotein lipase activity. J Lipid Res 24: 12, 1983.

18) Kubo M, Matsuzawa $Y$, Sudo $H$, et al: Specific modification of hepatic triglyceride lipase activity by ultracentrifugally separated serum lipoprotein fractions. J Biochem 88: 905, 1980.

19) Goldberg IJ, Paterniti N, Ginsberg HN, et al: The role of hepatic triglyceride lipase in primates. In: Schettler G, ed. Atherosclerosis VI. Berlin Heidelberg: SpringerVerlag: 624, 1983.

20) Olivecrona T, Bengtsson G, Osborne JC: Molecular properties of lipoprotein lipase: Effect of limited trypsin digestion on molecular weight and second structure. Eur J Biochem 124: 629, 1982.

21) Shirai K, Saito Y, Yoshida S: Post-heparin plasma hepatic triacylglycerol lipase-catalyzed tributyrin hydrolysis - Effect of trypsin treatment-. Biochem. Biophysica. Acta 794: 9, 1984.

22) Shirai K, Jackson RL, Quinn DM: Reciprocal effect of apolipoprotein C-II on the lipoprotein lipase catalyzed hydrolysis of p-nitrophenyl butyrate and trioleoylglycerol. J Biol Chem 257: 10200, 1982.

23) Komaromy M, Schotz MC: Cloning of rat hepatic lipase cDNA: Evidence for a lipase gene family. Proc Natl Acad Sci USA 84: 1526, 1987.

24) Bagdade JD, Porte D, Bierman EL: Steroid-induced lipemia. Arch Intern Med 125: 129, 1970. 